Article

\title{
Spatio-Temporal Profiling of Metarhizium anisopliae- Responsive microRNAs Involved in Modulation of Plutella xylostella Immunity and Development
}

\author{
Junaid Zafar ${ }^{1,+}$, Yuxin Zhang ${ }^{1,+}$, Junlin Huang ${ }^{1}$, Shoaib Freed ${ }^{2}$, Rana Fartab Shoukat ${ }^{1} \mathbb{D}$, Xiaoxia Xu $^{1, *}$ \\ and Fengliang Jin ${ }^{1, *}$
}

1 Laboratory of Bio-Pesticide Creation and Application of Guangdong Province, College of Plant Protection, South China Agricultural University, Guangzhou 510642, China; jz_jaam@yahoo.com (J.Z.); jzento57@gmail.com (Y.Z.); huangjunlinscau@163.com (J.H.); ranafartab@gmail.com (R.F.S.)

2 Laboratory of Insect Microbiology and Biotechnology, Department of Entomology, Faculty of Agricultural Sciences and Technology, Bahauddin Zakariya University, Multan 66000, Pakistan; sfareed@bzu.edu.pk

* Correspondence: xuxiaoxia111@scau.edu.cn (X.X.); jflbang@scau.edu.cn (F.J.)

+ These authors contributed equally to this work.

check for updates

Citation: Zafar, J.; Zhang, Y.; Huang, J.; Freed, S.; Shoukat, R.F.; Xu, X.; Jin, F. Spatio-Temporal Profiling of

Metarhizium anisopliae-Responsive microRNAs Involved in Modulation of Plutella xylostella Immunity and Development. J. Fungi 2021, 7, 942. https://doi.org/10.3390/jof7110942

Academic Editors: Ivan M. Dubovskiy and Tariq Butt

Received: 7 October 2021

Accepted: 1 November 2021

Published: 8 November 2021

Publisher's Note: MDPI stays neutral with regard to jurisdictional claims in published maps and institutional affiliations.

Copyright: (c) 2021 by the authors. Licensee MDPI, Basel, Switzerland. This article is an open access article distributed under the terms and conditions of the Creative Commons Attribution (CC BY) license (https:/ / creativecommons.org/licenses/by/ $4.0 /)$.

\begin{abstract}
Metarhizium anisopliae, a ubiquitous pathogenic fungus, regulates a wide array of the insect pest population. The fungus has been employed to control Plutella xylostella, an insecticideresistant destructive lepidopteran pest, which causes substantial economic losses in crops worldwide. Integration of modern gene-silencing technologies in pest control strategies has become more crucial to counter pesticide-resistant insects. MicroRNAs (miRNA) play essential roles in the various biological process via post-transcriptional gene regulation. In the present study, RNA-seq analysis of control (CK36h, CK72h) and fungal-infected (T36h, T72h) midguts was performed to reveal underlying molecular mechanisms occurring in larval midgut at different time courses. We aimed at exploring M. anisopliae-responsive miRNAs and their target genes involved in development and immunity. After data filtration, a combined set of 170 miRNAs were identified from all libraries. Interestingly, miR-281, miR-263, miR-1, miR-6094 and miR-8 were listed among the most abundantly expressed conserved miRNAs. Furthermore, we experimentally studied the role of differentially expressed miR-11912-5p in regulating corresponding target trypsin-like serine proteinase (Px_TLSP). The luciferase assay (in vitro) revealed that miRNA-11912-5p significantly downregulated its target gene, suggesting it might play a crucial role in defense mechanism of $P$. xylostella against $M .+$ anisopliae infection. We used synthetic miRNA mimic/inhibitor (in vivo), to overexpress/silence miRNA, which showed harmful effects on larval duration, survival and adult fecundity. Additionally, fungal application in the presence of mimics revealed enhanced sensitivity of $P$. xylostella to infection. Our finding provides an insight into the relatively obscure molecular mechanisms involved in insect midgut during the fungal infection.
\end{abstract}

Keywords: biocontrol; midgut; small RNA; gene silencing; diamond back moth

\section{Introduction}

Plutella xylostella (L.) (Lepidoptera: Plutellidae) is a major pest of cruciferous crops distributed throughout the world, causing severe economic damages. Imprudent use of chemical insecticides has led to various complications, such as environmental pollution and pesticide resistance [1,2]. Over the past few decades, the pest has developed resistance against various families of synthetic insecticides [3]. Arthropod Pesticide Resistance Database (APRD) ranked P. xylostella among the top 20 most resistant species [4]. P. xylostella was also the first insect species to have developed resistance against toxins from Bacillus thuringiensis [5]. Therefore, to combat resistance development, it is essential to probe for alternative control measures. 
Scientists have explored entomopathogenic fungi due to their ability to control susceptible, resistant, and multi-resistant arthropod populations [6,7]. These microbial insecticides attach to the host cuticle, germinate and penetrate hemolymph, leading to fungal growth inside the host, eventually producing and dispersing secondary infectious conidia [8]. Entomopathogenic fungi, Beauveria bassiana and Metarhizium anisopliae, have shown potential against various pests, including Aedes albopictus [9], Bemisia tabaci [10], Culex pipiens [11] and Spodoptera frugiperda [12]. Insects respond to pathogenic infections by initiating various immune pathways, activating transcription factors, and gene expressional changes [13]. Our recent study found that $M$. anisopliae could effectively control the P. xylostella population [14]. However, a comprehensive understanding of the molecular interplay between host-pathogen is required, which will help unravel innovative methods for incorporating fungus into pest management programs.

MicroRNAs (miRNAs) comprise a large family of single-stranded small non-coding RNAs ( $\sim 22$ nucleotides) that regulate the expression of genes by binding complementarily to the target sites in the mRNAs [15]. They are involved in the modulation of various biological processes, such as metabolism, immunity [16], and development [17] via posttranscriptional regulation either by obstructing mRNA translation or degrading it [18]. Suppression and overexpression of miRNAs can severely affect the normal development in insects, with potentially fatal consequences [19]. The use of synthetic miRNA mimics (overexpression) and inhibitors (suppression) has been proven prolific by targeting key genes [20]. In migratory locusts, miR-71 and miR-263 expressed in epidermis upregulate and produce molting-defective phenotypes [21]. In Bombyx mori, miR-14 overexpression leads to delayed larval development and produces smaller-sized larvae and pupa [22].

Entomopathogenic fungi have been extensively studied for host-pathogen interactions occurring at insect cuticle and hemolymph regulated by miRNAs $[23,24]$. However, the evidence regarding the immune and developmental challenges caused by entomopathogenic fungi in insect midgut, a key organ for various physiological processes such as development [25], immunity [26], reproduction [27], and stress response [28], is scarce. Even though researchers have investigated the possibility of oral infection in terrestrial arthropods, but the evidence suggests that even if ingested, Metarhizium spp. fails to germinate in the host gut. It could be attributed to a hostile environment (unfavorable digestive enzymes and $\mathrm{pH}$ ) present in the insect gut. However, evidence suggests that $B$. bassiana can infect through the gut, chiefly due to its toxic genes (Vip3A and Cry-like delta endotoxins) shared with bacterial pathogens $[29,30]$.

Despite penetration through the cuticle, fungal pathogens can also manipulate gut activities. For instance, entomopathogenic fungi modulate gut microbes and accelerate mortality [31]. Histological evidence suggests that entomopathogenic fungi, B. bassiana, destroy midgut epithelium after penetration through the cuticle, displacing columnar layer towards gut lumen with an increasing number of regenerative cells beneath it [32]. In Spodoptera littoralis larvae, when infected with three species of entomopathogenic fungi, i.e., Paecilomyces fumosoroseus, B. bassiana, and M. anisopliae lead to exfoliation of the midgut epithelium and disturbance of peritrophic membrane [33]. Fungal hyphae of $B$. bassiana colonized in the midgut musculature of termite, Odontotermes obesus followed by penetration into the gut lumen through epithelial cells and caused columnar cells to slough off, becoming disorganized, granular and hypertrophied [34]. Similarly, in B. mori, entomopathogenic fungi severely damaged the midgut tissues resulting in hyphal growth and ultimately death [35], signifying the importance of midgut during fungal infection. We theorized that if entomopathogenic fungi can cause dysbiosis, blockage and destruction of midgut epithelium, it is plausible that it could trigger the miRNA-mRNAs involved in the gut immunity and development.

The objective of the current study is to investigate the spatiotemporal host-pathogen interaction occurring within midgut after infection with $M$. anisopliae using next-generation RNA sequencing. Additionally, bioinformatics tools identified differentially expressed miRNAs and their potential target genes. Furthermore, we used different molecular approaches 
to study the miRNA-mRNA interactions. Finally, the suppression and overexpression of miRNA and its consequences on various biological parameters were explored.

\section{Materials and Methods}

\subsection{Fungal Infection and Small RNA Sequencing}

Entomopathogenic fungi, $M$. anisopliae, was used to infect the 3rd instar larvae of P. xylostella, while aqueous $0.05 \%$ Tween-80 (Sigma-P1754) was taken as control as described in our previous studies [14]. Midgut tissues from control (CK36h and CK72h) and infected (T36h and T72h) groups were dissected in phosphate buffer saline (PBS) using a sterilized dissection kit and snap-frozen in liquid nitrogen. Trizol Total RNA isolation Kit (Takara, Japan) was used to extract total RNA following the manufacturer's instructions. The concentration and integrity of RNA were determined by Nanodrop (Bio-Rad, Hercules, CA, USA) and Agilent 2100 Bioanalyzer (Agilent, Palo Alto, CA, USA), respectively. Briefly, RNAs were first ligated with a $3^{\prime}$ adapter followed by size fraction and ligation to $5^{\prime}$ adapter. Then, the small RNA libraries were constructed and sequenced using Illumina HiSeq ${ }^{\mathrm{TM}}$ 2500 by Gene Denovo Biotechnology Co. (Guangzhou, China).

\subsection{Bioinformatics Analysis of Small RNA Sequences}

To obtain clean data, raw reads were filtered to remove low-quality transcripts, removing reads containing $3^{\prime}$ and $5^{\prime}$ adapter and transcripts shorter than 18 nucleotides. High-quality reads were then mapped to the P. xylostella genome (GCA_000330985.1), and clean tags were aligned to the Rfam database (11.0) to identify and remove rRNA, scRNA, snoRNA, snRNA, and tRNA. Finally, the miRBase (Version 21) database was used to identify known miRNAs, while unannotated clean sequences were used to predict novel transcripts using Mireap_v 0.2 [36].

Three software, RNAhybrid, miRanda, and TargetScan were used to analyze and predict potential targets of $M$. anisopliae-responsive miRNAs. The intersection of these software was considered more credible and chosen as predicted miRNA target genes. Additionally, the Gene Ontology (GO) database and Kyoto Encyclopedia of Gene \& Genomes (KEGG) pathway enrichment analyses of all the predicted genes were performed for functional annotation. Differential expression analysis was performed by transforming the read counts into transcript per million (TPM) values. The corrected $p \leq 0.05$ was set as the threshold to determine significant enrichment of the gene sets.

\section{3. $R T-q P C R$ Validation}

To validate RNA-sequencing results, real-time quantitative PCR (RT-qPCR) was used. Subsequently, miRNAs and their targets were randomly selected, and RT-qPCR was performed using a Bio-Rad iQ2 optical system (Bio-Rad, Hercules, CA, USA) and SsoFast EvaGreen Supermix (Bio-Rad, Hercules, CA, USA) while U6/RPS13 were used as an internal control. The reaction protocol is as follows: $95^{\circ} \mathrm{C}$ for $30 \mathrm{~s}, 40$ cycles of $95^{\circ} \mathrm{C}$ for $5 \mathrm{~s}$, and $55{ }^{\circ} \mathrm{C}$ for $10 \mathrm{~s}$, and a dissociation curve was generated from 65 to $95{ }^{\circ} \mathrm{C}$ to confirm the purity [37]. In addition, among the differentially expressed miRNAs, miR-11912-5p and its target gene trypsin-like-serine proteinase (Px_TLSP) were expressed during both time points and was selected for further functional studies. Data analysis was performed using the $2^{-\Delta \Delta C T}$ method [38].

\subsection{In Vitro Luciferase Validation}

The HEK293T cells used in the current study were cultured in Dulbecco's Modified Eagle Medium (DMEM) (Gibco, Grand Island, NY, USA) and supplemented with 10\% fetal bovine serum. Cells were maintained at $37{ }^{\circ} \mathrm{C}$ with $5 \% \mathrm{CO}_{2}$. The binding site of $P x \_T L S P$ (Gene ID: 105383574) was amplified and cloned into psiCHECK2 vector (Promega, Madison, WI, USA) containing the restriction enzymes sites NotI and XhoI. A mimic of miR-11912-5p was designed and synthesized (GenePharma, Shanghai, China). 
The cells were co-transfected with $800 \mathrm{ng}$ of the reporter vector and miRNA mimic at the ratio of 1:3 using Lipofectamine ${ }^{\mathrm{TM}} 2000$ reagent (Invitrogen, Waltham, MA, USA) following the manufacturer's guidelines. Cells were transfected for $48 \mathrm{~h}$ and harvested for dual luciferase assay. Renilla luciferase and Firefly activities were measured using the Dual-GLO ${ }^{\circledR}$ Luciferase Assay System (Promega, USA) with a luminometer (Promega, USA). Results are expressed as the ratio Renilla/firefly luciferase activity (Mean \pm SEM) at $p<0.01$. Primer sequences and the mimics/inhibitors used in this study are given (Table S7).

\subsection{Overexpression and Inhibition Treatment of miRNA In Vivo}

The synthetic miRNA mimics and inhibitors were used to perform the functional studies of miRNA in vivo. Briefly, $1 \mathrm{~g}$ artificial diet prepared in RNAse-free water was enriched with $20 \mu \mathrm{L}$ miR-11912-5p mimics $(20 \mu \mathrm{M})$, and $10 \mu \mathrm{L}$ inhibitor $(20 \mu \mathrm{M})$ [39]. Susceptible 3rd instar larvae $(n=60)$ were fed on the treated and control diet for $24 \mathrm{~h}$. The successful delivery of mimics / inhibitors was verified using RT-qPCR. The digestive activity of Px_TLSP in the mimic treated larval stage was measured using N $\alpha$-Benzoyl-DLArg-p-nitroanilide (BAPNA, Sigma). Next, 4 mM BAPNA was prepared in $100 \mathrm{mM}$ Tris, $\mathrm{pH} 8.0$, which contained $20 \mathrm{mM} \mathrm{CaCl}_{2}$ and was used as the substrate solution [40]. The gut was homogenized in PBS and incubated at $37^{\circ} \mathrm{C}$. The experiments were performed in microtiter plates with a final volume of $100 \mu \mathrm{L}$ containing $10 \mu \mathrm{L}$ gut content and $40 \mu \mathrm{L}$ substrate. The absorption was measured at $405 \mathrm{~nm}$ using a microplate reader (Bio-Rad). Furthermore, larval duration and mortality were calculated among all the groups. The adults, upon emergence, were paired (1 pair/cage) for egg-laying, and average fecundity was calculated on a daily basis.

\subsection{Fungal Bioassay}

To investigate the role of miR-11912-5p in P. xylostella larval susceptibility to entomopathogenic fungi, M. anisopliae was used as an infection. Third instar larvae were fed on a diet mixed with mimic, control mimic, and control, and later infected with the fungal solution. Mortality data were recorded every $24 \mathrm{~h}$. Larvae with no movement were considered dead. Cadavers were placed in humid chambers to observe conidial growth.

\section{Results}

\section{1. sRNA Sequencing Analysis}

Small RNA libraries were constructed to identify miRNAs in M. anisopliae-infected P. xylostella larval midgut using next-generation Illumina RNA sequencing. Totally, $16,450,812$ (CK36h) 17,025,780 (T36h), 16,294,807, (CK72h), and 18,257,426 (T72h) high-quality reads were obtained. After quality check by filtering the sequences $<18 \mathrm{nt}$, adapters, and lowquality reads, a total of 10,693,027 (CK36h), 10,814,199 (T36h), 12,711,662 (CK72h), and $13,740,439$ (T72h) were obtained for further analysis (Table S1). The clean reads were then mapped to the P. xylostella genome (GCA_000330985.1) resulting in 6,491,737 (60.71\%) 7,288,770 (67.40\%), 9,135,560 (71.86\%), 9,782,371 (72.56\%) matched reads in CK36h, T36h, $\mathrm{CK} 72 \mathrm{~h}$, and $\mathrm{T} 72 \mathrm{~h}$, respectively (Table S2).

Subsequently, the clean reads were categorized into miRNA, rRNA, snRNA, snoRNA, rRNA, tRNA, and unannotated ensuing priority rule of rRNA, etc.; GenBank > Rfam) > known miRNA $>$ repeat $>$ exon $>$ intron. All the clean reads were divided into different categories including miRNA, rRNA, snRNA, snoRNA, tRNA, and unannotated (unann) following priority rule of rRNA etc.; (GenBank $>$ Rfam) $>$ known miRNA $>$ repeat $>$ exon $>$ intron [41]. The overall sRNA class composition of each library is presented (Figures S1 and S2).

\subsection{Identification of M. anisopliae Responsive Known and Novel miRNAs}

We filtered and compared the miRNA sequences from previously reported [42] and identified known miRNAs; after filtering those with read count $<10$ in all libraries, 127 known miRNAs were found (Table S3). Notably, the abundantly expressed miRNAs, 
included miR-bantam-3p, miR-281-3p, miR-1-3p, miR-8-3p, and miR-6094-3p, in response to $M$. anisopliae infection. The top 10 abundantly expressed miRNAs are presented in Figure 1. The remaining unmatched sequences were used to predict novel miRNAs using Mireap_v 0.2 following standard criteria, which resulted in the identification of 43 novel miRNAs (Table S4).

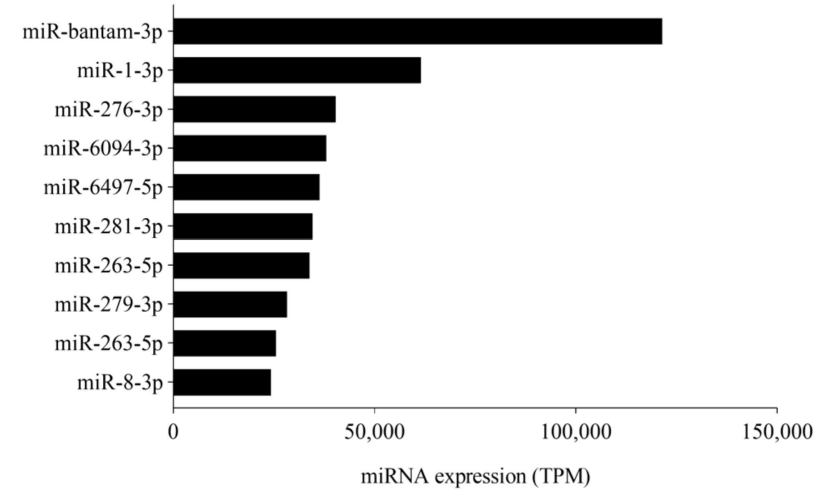

Figure 1. Top 10 abundantly expressed miRNAs in P. xylostella after M. anisopliae infection over the time course. Average expression values of time courses ( $36 \mathrm{~h}$ and $72 \mathrm{~h}$ ) are presented. TPM denotes transcript per million.

\subsection{Identification of Differentially Expressed miRNAs and Target Predictions}

Differential expression analysis was carried out to determine variations in miRNA levels followed by infection from $M$. anisopliae. After normalization of read counts by transforming them into transcript per million (TPM) values, we found that 20 (T36h) and 15 (T72h) known miRNAs were identified as differentially expressed, compared to control (Table S5). Similarly, 12 (T36h) and 14 (T72h) novel miRNAs were also identified as differentially expressed (Table S6). Overall, most of the differentially expressed miRNAs were upregulated, followed by fungal infection and gradually downregulating as time progressed.

\subsection{RT-qPCR Validation of miRNAs and Their Targets}

To validate the identified miRNAs and their respective targets, RT-qPCR was performed (Figure 2). We focused mainly on immunity and development-related miRNAs and their target genes from differentially expressed transcripts commonly predicted by bioinformatic tools. Negative correlation was observed between miRNAs and the target genes among the control and the treatment groups. The expression level of $\beta$ GRP ( $\beta$ $1,3-$ Glucan recognition protein), a gene involved in recognition of fungal pathogen, was significantly downregulated by miR-67-5p at the initial stage of infection $(36 \mathrm{~h})$ with a gradual increase at $72 \mathrm{~h}$. (Figure 2a). The expression level of NF- $\mathrm{KB}$ (nuclear factor kappalight-chain-enhancer of activated B cells) responsible for downstream stimulation of specific immune genes and triggering of antimicrobial peptides was continually downregulated by miR-9 (Figure 2b). Similarly, the expression level of Hemolin, a gene involved in the pathogen-induced immune responses, was significantly downregulated by miR-8117-3p at 36 and $72 \mathrm{~h}$ post infection compared to control (Figure 2c). Chymotrypsin, a major digestive protease in larval midgut, was negatively affected by abundantly expressed miR-6941-5p (Figure 2d). However, the results showed a slight discrepancy in the RNA sequencing analysis, primarily due to the differences between the two techniques. 


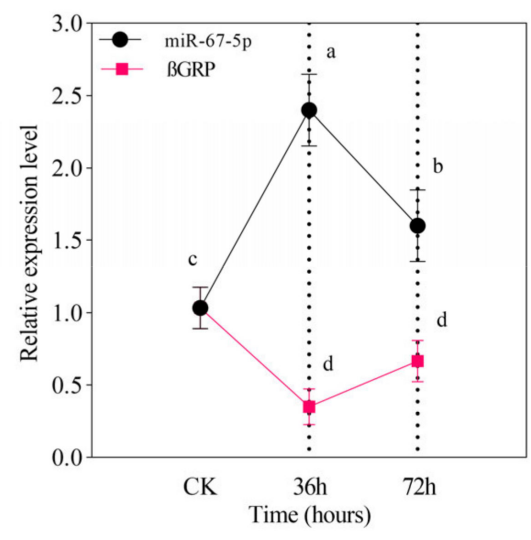

(a)

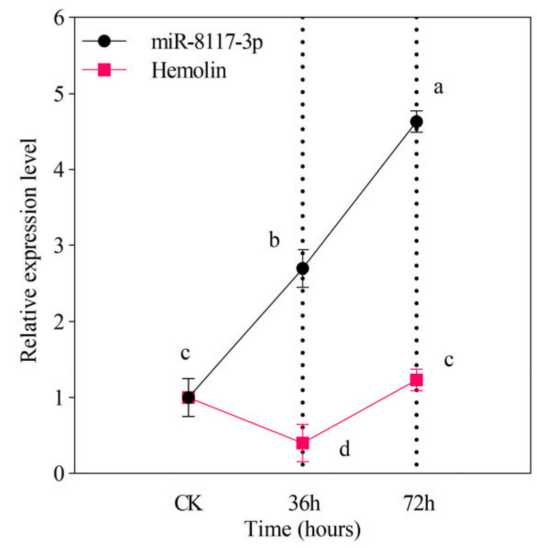

(c)

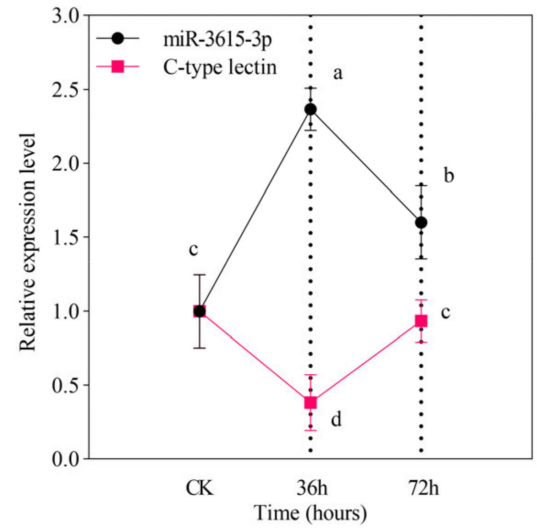

(e)

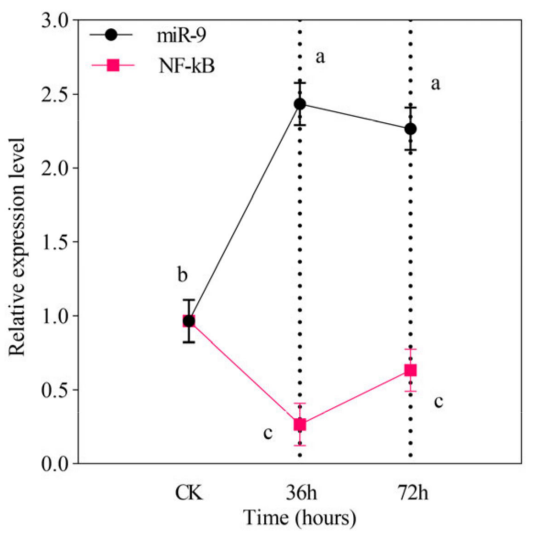

(b)

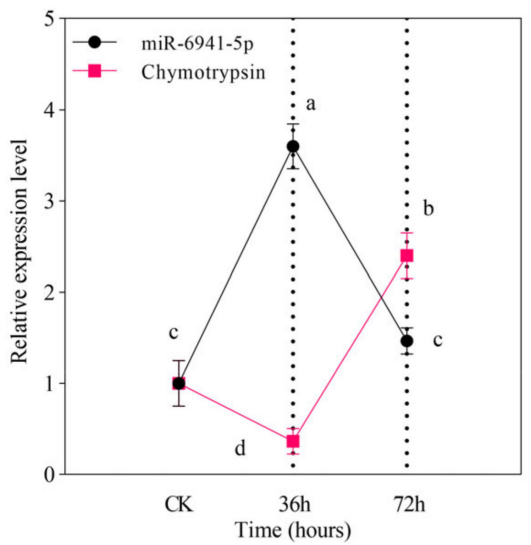

(d)

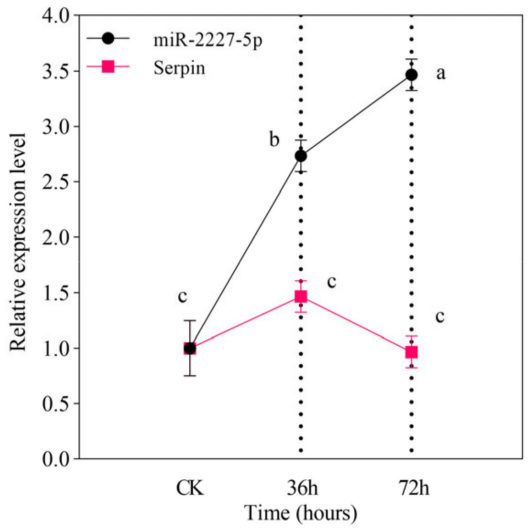

(f)

Figure 2. RT-qPCR validation of known miRNAs and their targets mRNAs. (a) miR-67-5p target $\beta$ GRP; (b) miR-9 target NF-кB; (c) miR-8117-3p target Hemolin; (d) miR-6941-5p target Chymotrypsin; (e) miR-3615-5p target C-type lectin; (f) miR-2227-3p target Serpin followed by M. anisopliae infection at different course (36 and $72 \mathrm{~h}$ ). Relative fold change of mRNA and miRNAs were normalized using RPS13 and U6, respectively, as an internal control. Error bars show $95 \%$ confidence intervals (CI). Letters indicate significant differences at $p<0.001$. 


\subsection{Prediction and Annotation of miRNA Targets and Functional Classification}

We used three software (TargetScan, miRanda, and RNAhybrid) to predict the potential miRNA targets. The results showed that 16,883 shared spots as target predictions of 170 miRNAs (Figure 3). Overall, 28,950 common spots were identified between miRanda and TargetScan, 27,837 between RNAhybrid and TargetScan, and 16,992 between miRanda and RNAhybrid. GO enrichment analysis was carried out to understand the functions of target genes in biological processes, cellular components, and molecular functions (Figures S3 and S4). Furthermore, KEGG enrichment pathway analysis was used to categorize M. anisopliae-responsive target genes of miRNAs; the top 20 enriched categories included lysosomes, transport, various signaling pathways, and more (Figures S5 and S6).

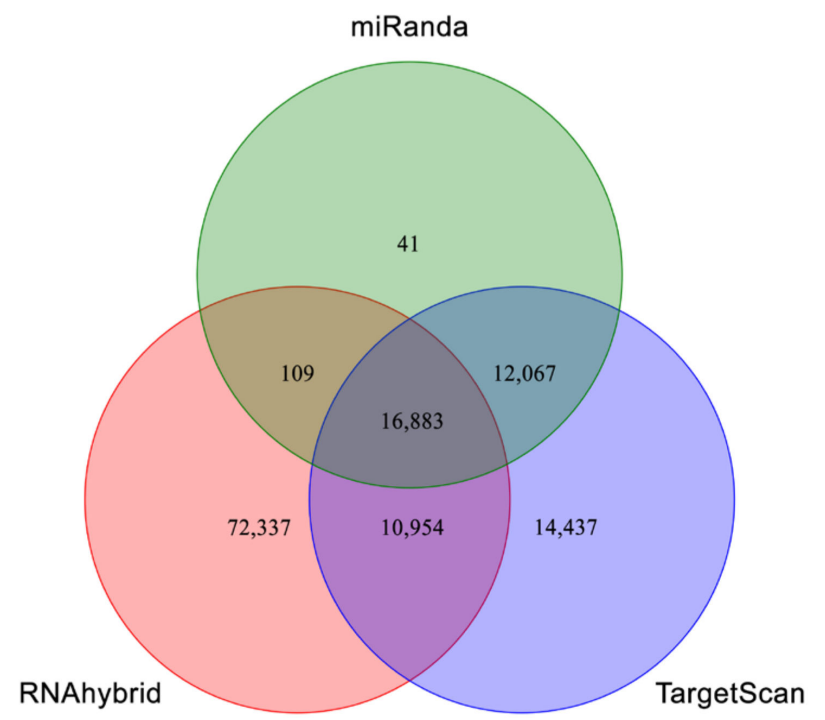

Figure 3. Potential target genes of miRNAs identified in P. xylostella followed by M. anisopliae infection. Venn diagram displays the number of miRNA target sites identified by each software (miRanda, TargetScan, and RNAhybrid).

Additionally, we compared differentially expressed genes from current studies with our previous libraries where $P$. xylostella was infected with bacterial and fungal pathogens [43-45] to filter out immune-related target genes. Interestingly, we found that miR-11912-5p was among the differentially expressed miRNAs in P. xylostella larvae during M. anisopliae infection, which resulted in the downregulation of its target gene trypsin-like serine proteinase $\left(P x_{-} T L S P\right)$. Trypsin is a major enzyme present in insect midgut known to perform a key role in digestion, development, and survival [46], indicating that it might play a crucial role in the defense mechanism.

\subsection{In Vitro Luciferase Validation}

The bioinformatics tools (TargetScan, RNAhybrid, and miRanda) predicted the Px_TLSP as a potential target site of miR-11912-5p (Figure 4a). To experimentally verify the interaction, synthetic miR-11912-5p mimic were co-transfected with HEK293T cells. We observed significantly less luciferase activity $48 \mathrm{~h}$ post transfection compared to that in control (Figure 4b). 


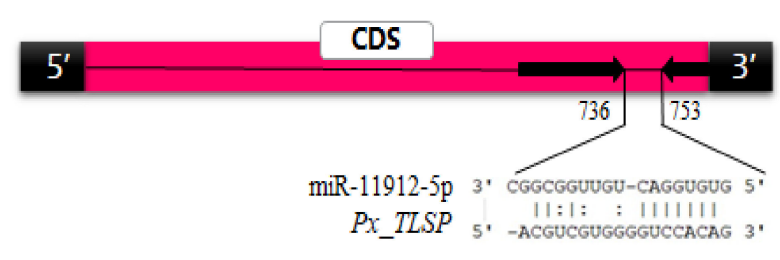

(a)

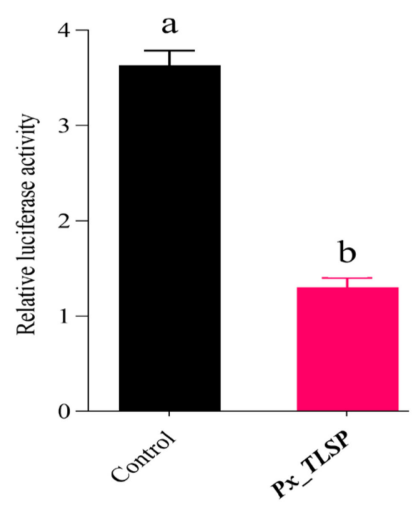

(b)

Figure 4. Prediction and validation of miR-11912-5p and its target site in vitro. (a) Predicted target site of miR-11912-5p in $P x \_T L S P$ by TargetScan, RNAhybrid and miRanda; $(\mathbf{b})$ validation of miR-11912-5p-Px_TLSP direct sequence interaction by dual luciferase assays using HEK293T cells $48 \mathrm{~h}$ after co-transfection with the psi-CHECK2 construct presented as Mean \pm SEM of three biological replicates. Letters indicate significant differences $p<0.01$.

\subsection{Overexpression and Inhibition Treatment of miRNA In Vivo}

To determine the effects of miR-11912-5p on its target gene in vivo, we detected the expression levels of $P x_{-}$TLSP after miRNA mimic and inhibitor application. We quantified the expression of $P x_{-} \_L S P$ in larvae fed on miR-11912-5p mimic/inhibitor (Figure 5). The relative expression levels of the $P x_{-} T L S P$ gene showed a significant reduction in mimicfed larvae (Figure 5a), while contrastive expressions were observed in the group fed on inhibitors (Figure 5b), implying successful delivery of mimic/inhibitors in vivo.

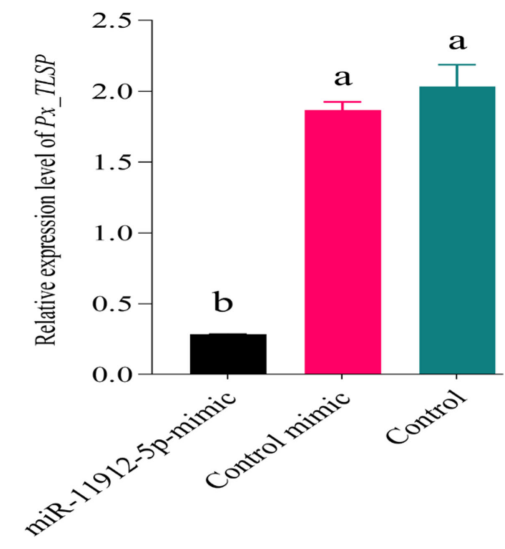

(a)

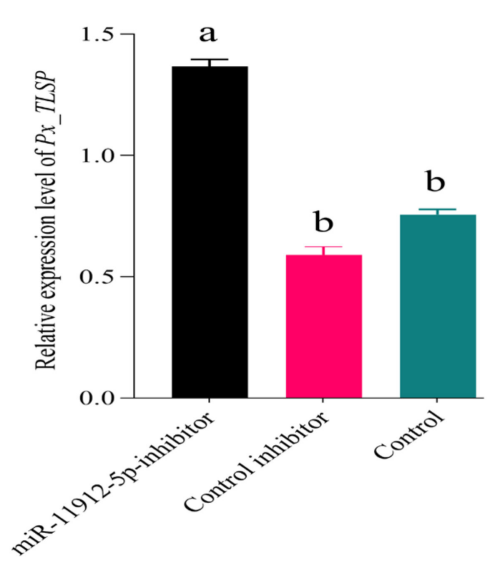

(b)

Figure 5. RT-qPCR expression levels of Px_TLSP in P. xylostella larvae fed on (a) miR-11912-5p-mimic, control mimic, control, and (b) miR-11912-5p-inhibitor, control inhibitor, and control. Error bars show 95\% confidence intervals (CI). Letters indicate significant differences at $p<0.001$.

Additionally, we performed a trypsin enzyme assay to check if the decline of Px_TLSP in the presence of miR-11912-5p mimics parallels with low trypsin activity in the gut of P. xylostella. The results indicated significantly less tryptic activity in the gut extracts from larvae fed on mimic than control (Figure 6). 


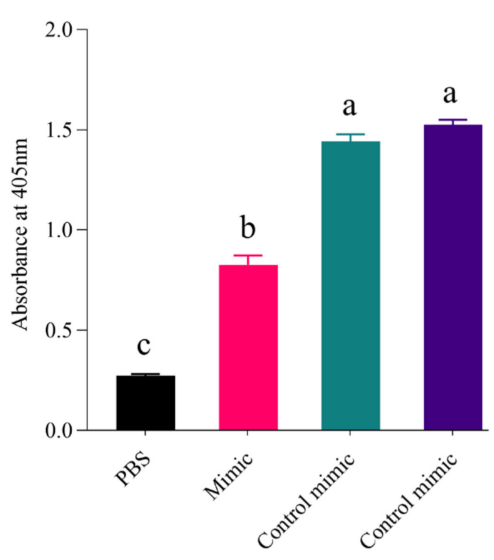

Figure 6. Trypsin enzyme activity in gut extracts from larvae fed on miR-11912-5p-mimic, control mimic, control, and PBS (no gut content). Three technical and two biological replicates per treatment were analyzed. Letters indicate significant differences at $p<0.001$.

\subsection{Impact on Development, Fecundity, and Survival}

Trypsin has been involved in the regulation of development and digestion [47]; we theorized that the application of synthetic miR-11912-5p mimic and inhibitor could potentially impact the larval development. Treatment of $P$. xylostella larvae with miR-11912-5p mimic resulted in detrimental effects on larval development, fecundity, and survival (Figure 7). The increased larval duration (12 d) was observed in mimic-treated larvae compared to control mimic and control (9d) ( $p<0.0001)$ (Figure 7a). The silencing of trypsin also showed drastic effects on survival of $P$. xylostella. The larvae fed on control mimic and control led to successful pupation of $93 \%$ (on avg.) larvae (Figure $7 \mathrm{~b}$ ), whereas $68 \%$ of mimic-treated larvae entered into pupation while the remaining larvae failed mid (larval-pupation) stage and eventually died. The successfully emerged adults from the mimic-treated group were paired, and adult fecundity was documented daily. We noticed a reduction of $63 \%$ $(p<0.0001)$ in fecundity among adults that emerged from mimic fed larvae compared to control (Figure 7c).

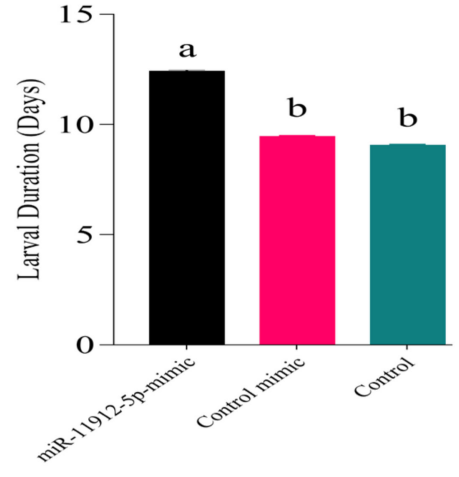

(a)

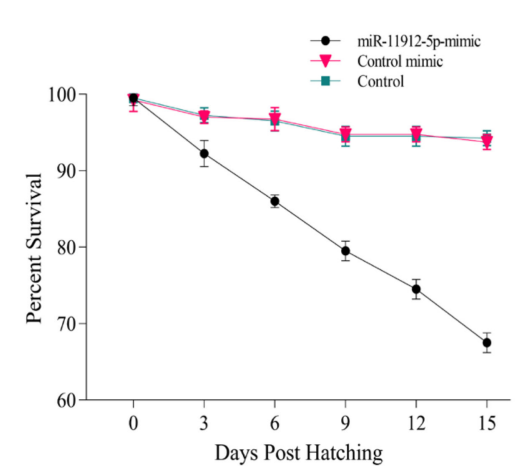

(b)

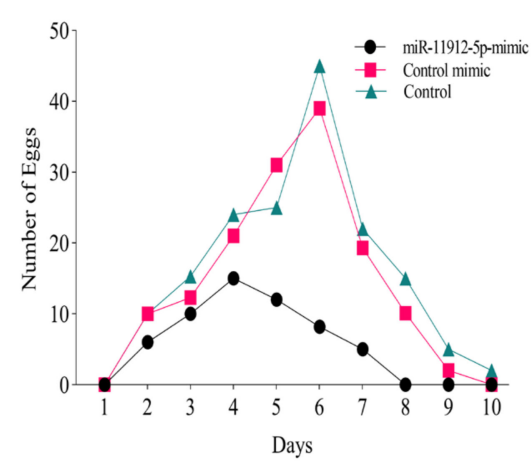

(c)

Figure 7. Impact of mimic administration on P. xylostella larval development, survival and fecundity. (a) average larval duration; (b) survival percentage of P. xylostella larvae fed on miR-11912-5p-mimc, control mimic and control; (c) average adult fecundity from start of the egg laying. Error bars represent standard deviations of mean values from independent replicates. Letters indicate significant differences at $p<0.05$.

Impact of silencing Px_TLSP using miR-11912-5p can be seen (Figure 8). Abnormal larval growth and failed pupation was observed in mimic-treated group (Figure 8b) compared to 
control (Figure 8a) The larvae treated with miRNA inhibitor did not show any significant differences in the parameters mentioned above.

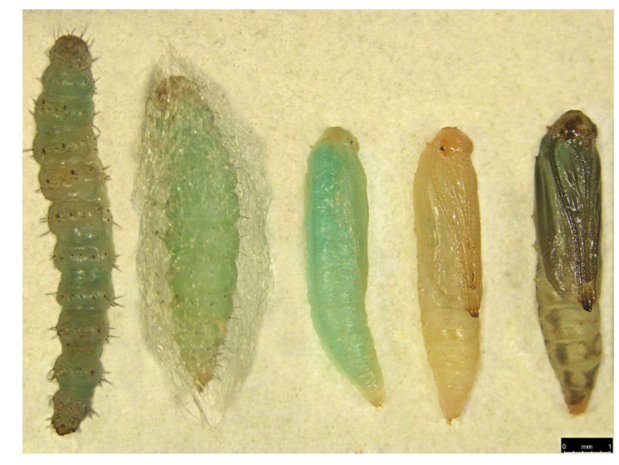

(a)

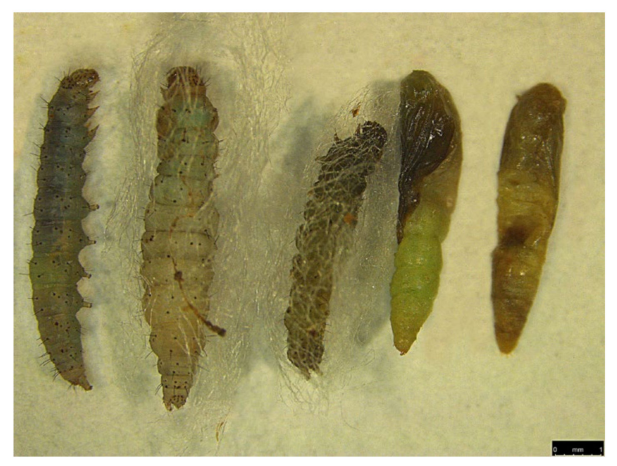

(b)

Figure 8. Impact of miR-11912-5p-mimic administration on P. xylostella larval development and pupal formation. (a) Larvae showing normal growth leading to successful pre-pupation and pupation in untreated population (left to right); (b) abnormal development during larval stage leading to failed pre-pupation and pupation in miR-11912-5p mimic-fed population (Left to Right).

\subsection{Fungal Susceptibility}

We investigated the role of mimics by enriching the larval diet and exposing the starved third instar larvae for $24 \mathrm{~h}$. Larvae were then treated with $M$. anisopliae to evaluate the susceptibility. We found that larvae fed on mimic proved to be more sensitive to the fungal infection than those without (Figure 9). Maximum mean mortality (93\%) was reported in the miR-11912-5p mimic, and M. anisopliae group, followed by $84.25 \%$ in the M. anisopliae-treated group, suggesting that mimic-treated larvae could potentially become more susceptible to fungal infection.

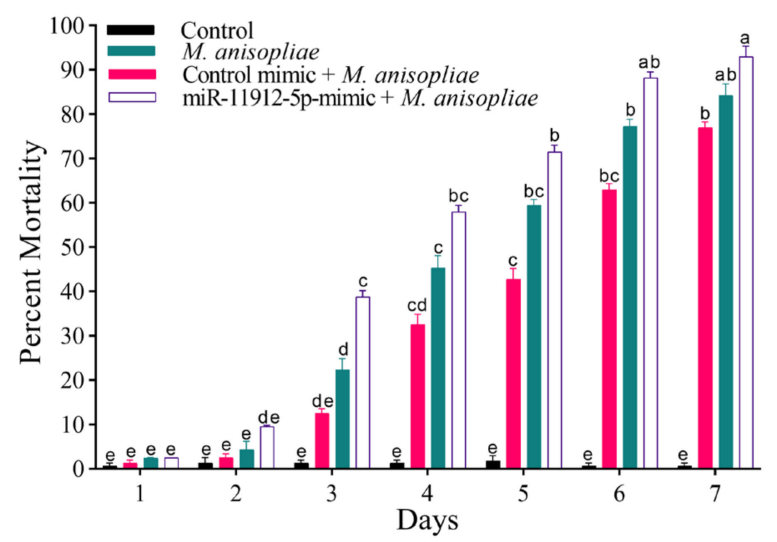

Figure 9. Percent mortality in P. xylostella followed by M. anisopliae infection. Mortality was recorded until seven days after every $24 \mathrm{~h}$. Error bars show 95\% confidence intervals (CI). Letters indicate significant differences at $p<0.05$.

The confirmation of fungal pathogenicity was verified by placing carcasses in a humid chamber for conidial growth (Figure 10). 


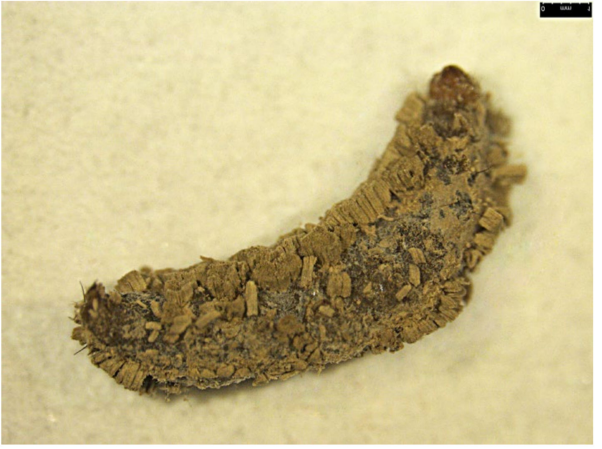

(a)

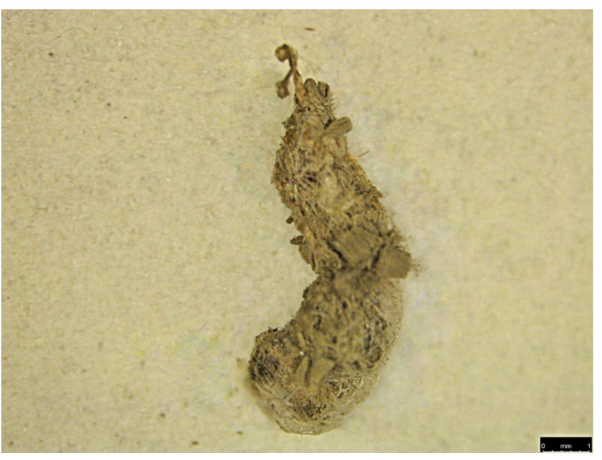

(c)

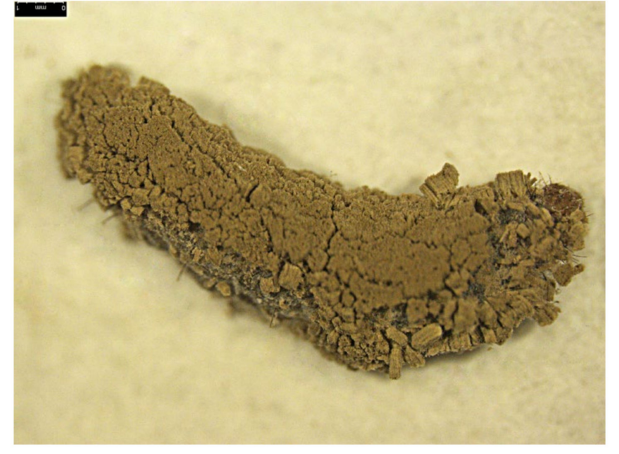

(b)

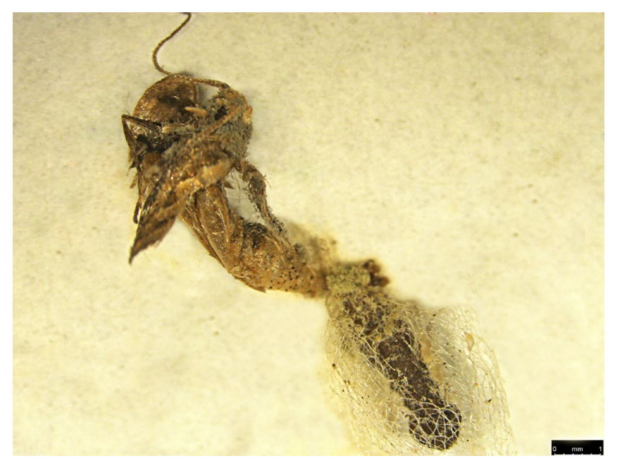

(d)

Figure 10. Fungal growth on various stages of P. xylostella infected with $M$. anisopliae. (a) Fungal growth over ventral region of larval body; (b) fungal growth over dorsal surface of larval stage; (c) fungal growth during pupal stage; (d) fungal infection resulting in failed adult emergence.

\section{Discussion}

The success of insects in adverse environments indicates the advanced defense mechanisms employed by these organisms, but they have often been targeted and killed by specialized pathogenic fungi. These cross-kingdom host-pathogen interactions have resulted in sustainable populations of both species. Next-generation RNA sequencing and bioinformatic tools have enabled us to unravel host-pathogen interactions in individual tissues. Entomopathogenic fungi have been frequently studied for their interaction with host integument in neutralizing their defenses, but the information regarding their impact on the host midgut is scarce. Histological and ultrastructural studies suggest that entomopathogenic fungi, B. bassiana, after penetration through cuticle in C. pipiens, significantly destroys the midgut [48]. Midgut tissues of fungi-infected Galleria mellonella larvae showed progressive destruction of the columnar cell after cuticular penetration [32]. Damaged crypts of the midgut and vegetative growth of entomopathogenic fungi in the digestive canal can cause mechanical blockage and is one of the reasons for the insect death after infection $[49,50]$.

In insects, miRNAs have been involved in various biological processes such as development, immunity, reproduction, and host-pathogen interactions [51]. RNAseq analysis revealed 170 miRNAs (127 known and 43 novel) from $M$. anisopliae-infected P. xylostella. Bantam was the most abundantly expressed miRNA, known to perform various roles in insects such as cell proliferation, apoptosis inhibition, modulating the ecdysone signaling pathway, and immunity [52,53], implying its importance in P. xylostella.

The top 10 abundantly expressed miRNAs in our studies, e.g., miR-281, miR-263, miR-8, and miR-279, have been previously described among highly expressed miRNAs in P. xylostella [54,55]. These miRNAs are known to play critical regulatory roles in different insects [56]. For instance, miR-8 increases the susceptibility of $P$. xylostella larvae to entomopathogenic fungi by regulating the Toll pathway and negatively affecting antimicrobial peptides (AMP) [20]. Similarly, miR-281, a midgut-specific miRNA was also 
listed in abundantly expressed miRNAs. In A. albopictus, the dengue virus (DENV) promotes its replication by exploiting miR-281, suggesting that pathogen can manipulate host miRNA for its advantage [57]. Likewise, miR-14 was also found to be abundantly expressed in our studies. MiR-14, investigated from the larval midgut of lepidopteran pest $S$. frugiperda, showed high expression levels in the sixth instar, potentially regulating metamorphosis [58]. It is plausible that these miRNAs play critical modulatory roles in the midgut of P. xylostella larvae during fungal infection. Moreover, miR-263 and miR-279 have been detected previously from P. xylostella infected with destruxin, a key virulence factor of entomopathogenic fungi, M. anisopliae [43]. Similarly, let-7, another conserved miRNA known to play an important role in development [59] and immunity [60], was also recorded among the abundantly expressed miRNAs, inferring its critical role in P. xylostella immunity and development. The novel miRNAs found in our studies showed comparatively low expression levels as opposed to the conserved, possibly due to the participation of conserved miRNAs in different biological processes [61].

Fungal infections can lead to changes in the expression level of miRNAs in several insect species [62]. Several differentially expressed miRNAs were found in the current study, followed by infection from entomopathogenic fungi, M. anisopliae. MiR-92 expression level upregulated upon pathogen infection, and its role has been examined in A. albopictus and Culex quanificatus development [63], signifying its potential in host-pathogen interaction. Similarly, miR-317 was among differentially expressed miRNAs at $36 \mathrm{~h}$, which is known to negatively modulate Drosophila toll immune responses and downregulate AMP productions [64], indicating its critical role in P. xylostella survival. Additionally, miR-8517 found in our studies have been reported previously from the pathogen-infected midgut of $P$. xylostella [65]. However, miR-2, a conserved miRNA, was listed amongst abundantly expressed miRNA, yet its expression level did not vary among treatments. Similar to our findings, miR-2 has shown high expression levels in different insect libraries including Apis mellifera, B. mori, and Tribolium casteneum [66]. The miR-2 family has been functionally studied for a critical role in Blattella germanica metamorphosis [67].

MiRNA mimics/inhibitors have been effectively used to establish the role of miRNAs in various insects $[68,69]$. In the present study, bioinformatic tools predicted that miR$11912-5 p$ could potentially target Px_TLSP (trypsin-like serine proteinase), followed by infection. Proteases, especially trypsin and chymotrypsin, are predominately present in insect midgut during larval stages and play a central role in the biological process, such as digestion and development [70]. In previous studies, trypsin-like serine proteases were among differentially expressed genes in P. xylostella larvae followed by entomopathogenic fungi, Isaria fumosorosea [44] infection, suggesting their critical role. To experimentally validate the role of miR-11912-5p in the regulation of $P x_{-}$TLSP in vitro, we performed dual luciferase assay. Our results indicated that miR-11912-5p could significantly downregulate $P x \_T L S P$, suggesting its potential role in fungal infection. Similarly, miR-2b-3p could significantly downregulate the expression level of trypsin followed by pathogen infection in P. xylostella larvae, supporting our findings [45].

Oral administration of miR-11912-5p mimic significantly affected larval development, survival, and adult fecundity. We observed a substantial increase in larval duration, whereas $32 \%$ of larvae failed to survive and died between the intermediate (larvae-pupae) stage. Similarly, we observed reduced fecundity, as previously reported in H. armigera where trypsin-like serine protease $(H a-T L P)$, present in the gut, was silenced by har-miR$2002 \mathrm{~b}$ mimics, which led to drastic effects on larval development and adult fecundity while also causing significant mortality [71]. Gene silencing technology can be used as a powerful method for controlling pests by regulating vital genes [72]. Spodoptera exigua larvae was adversely affected and caused significant mortality when it was orally fed with synthetic miRNA mimics (miR-9, miR-10-1a, and miR-4924), supporting our current findings [73]. Similarly, transgenic tobacco plants were developed capable of producing miR-24, which could potentially inhibit the H. armigera molting process with fatal consequences [74]. In rice plants, a cowpea trypsin inhibitor (CpTI) has shown significant resistance against 
rice borers [75]. Likewise, a trypsin inhibitor purified from Sapindus mukorossi (SMTI) has proven effective against Bactrocera cucurbitae, affecting larval growth and development [76].

Furthermore, mimic-fed P. xylostella larvae showed enhanced sensitivity to M. anisopliae infection, signifying the regulatory role of miRNA. Meterhizium spp. can potentially sense defense molecules produced by insects, including AMP and proteinase inhibitors and then launch a counterattack by releasing its proteinases and degrading these compounds [77]. In P. xylostella, miR-7a, miR-8519, and miR-189942 mimic application-increased susceptibility of insecticide resistant population $[18,78]$. The effects of $M$. anisopliae in midgut of migratory locust was investigated and it was reported that trypsin and chymotrypsin activity varied upon infection [79], suggesting the complex host-pathogen interaction.

\section{Conclusions}

In conclusion, we identified 127 known and 43 novel miRNAs from M. anisopliaeinfected P. xylostella larval midgut. Additionally, miR-11912-5p in vitro validation revealed its significant interaction with trypsin-like serine proteinase (Px_TLSP) after fungal infection. We used synthetic mimic/inhibitors to overexpress and silence miRNA in vivo, which adversely affected larval duration, survival, and adult fecundity. The application of M. anisopliae in presence of mimic indicated that it could potentially enhance susceptibility towards infection. The study provides crucial information in establishing the modern genesilencing technologies to counter resistant insect pest infestations. The current study also laid the foundation for further research to understand the spatiotemporal host pathogen interactions occurring in insect midgut, a vital organ for several biological processes.

Supplementary Materials: The following are available online at https: / www.mdpi.com/article / 10.3390/jof7110942/s1: Table S1: The classification of total small RNA tags of the Plutella xylostella; Table S2: The mapping statistics of sRNAs from libraries of Plutella xylostella; Table S3: Expression profiles of Metarhizium anisopliae-responsive known miRNAs; Table S4: Expression profiles of Metarhizium anisopliae-responsive novel miRNAs; Table S5: Differential expression of Metarhizum anisopliae-responsive known miRNAs; Table S6: Differential expression of Metarhizium anisopliaeresponsive novel miRNAs; Table S7: The primers used in the current study; Figure S1: Small RNA composition of control (CK36h) and treatment (T36h) in all replicates post-infection; Figure S2: Small RNA composition of control (CK72h) and treatment (T72h) in all replicates post-infection; Figure S3: Gene ontology annotation of target genes of miRNAs in Plutella xylostella after Metarhizium anisopliae infection (CK36h vs. T36h); Figure S4: Gene ontology annotation of target genes of miRNAs in Plutella xylostella after Metarhizium anisopliae infection (CK72h vs. T72h); The abscissa is the GO annotation and the ordinate left is the gene number; Figure S5: Kyoto Encyclopedia of Genes \& Genomes classification of target genes in Plutella xylostella after Metarhizium anisopliae infection (CK36h vs. T36h); Figure S6: Kyoto Encyclopedia of Genes \& Genomes classification of target genes in Plutella xylostella after Metarhizium anisopliae infection (CK72h vs. T72h); The abscissa is the KEGG classification and the ordinate left is the gene number.

Author Contributions: Conceptualization, J.Z. and Y.Z.; methodology, J.Z. and Y.Z.; formal analysis, J.Z. and R.F.S.; investigation, J.Z. and J.H.; resources, X.X.; data curation, J.Z. and R.F.S.; writingoriginal draft preparation, J.Z.; writing—review and editing, X.X. and F.J.; visualization, X.X.; supervision, F.J.; project administration, S.F. and F.J.; funding acquisition, X.X. and F.J. All authors have read and agreed to the published version of the manuscript.

Funding: This work was supported by grants from the National Natural Science Foundation of China (31972345), Natural Science Foundation of Guangdong, China (2020A1515010300, 2019A1515011221), and the Key-Area Research and Development Program of Guangdong Province (2018B020205003).

Institutional Review Board Statement: Not applicable.

Informed Consent Statement: Not applicable.

Data Availability Statement: Not applicable. 
Acknowledgments: We are very grateful to the editors and reviewers for their helpful and constructive comments.

Conflicts of Interest: The authors declare no conflict of interest.

\section{References}

1. Yusoff, N.; Abd Ghani, I.; Othman, N.W.; Aizat, W.M.; Hassan, M. Toxicity and sublethal effect of farnesyl acetate on diamondback moth, Plutella xylostella (L.) (Lepidoptera: Plutellidae). Insects 2021, 12, 109. [CrossRef] [PubMed]

2. Li, Y.; Sun, H.; Tian, Z.; Li, Y.; Ye, X.; Li, R.; Li, X.; Zheng, S.; Liu, J.; Zhang, Y. Identification of key residues of carboxylesterase PxEst-6 involved in pyrethroid metabolism in Plutella xylostella (L.). J. Hazard. Mater. 2021, 407, 124612. [CrossRef] [PubMed]

3. Wang, X.; Wu, Y. High levels of resistance to chlorantraniliprole evolved in field populations of Plutella xylostella. J. Econ. Entomol. 2012, 105, 1019-1023. [CrossRef] [PubMed]

4. Shen, J.; Li, Z.; Li, D.; Wang, R.; Zhang, S.; You, H.; Li, J. Biochemical mechanisms, cross-resistance and stability of resistance to metaflumizone in Plutella xylostella. Insects 2020, 11, 311. [CrossRef]

5. Liu, Z.; Fu, S.; Ma, X.; Baxter, S.W.; Vasseur, L.; Xiong, L.; Huang, Y.; Yang, G.; You, S.; You, M. Resistance to Bacillus thuringiensis Cry1Ac toxin requires mutations in two Plutella xylostella ATP-binding cassette transporter paralogs. PLoS Pathog. 2020, 16, e1008697. [CrossRef]

6. Alonso-Díaz, M.Á.; Fernández-Salas, A. Entomopathogenic fungi for tick control in cattle livestock from Mexico. Front. Fungal Biol. 2021, 2, 18. [CrossRef]

7. Shoukat, R.F.; Zafar, J.; Shakeel, M.; Zhang, Y.; Freed, S.; Xu, X.; Jin, F. Assessment of lethal, sublethal, and transgenerational effects of Beauveria bassiana on the demography of Aedes albopictus (Culicidae: Diptera). Insects 2020, 11, 178. [CrossRef]

8. Shin, T.Y.; Lee, M.R.; Park, S.E.; Lee, S.J.; Kim, W.J.; Kim, J.S. Pathogenesis-related genes of entomopathogenic fungi. Arch. Insect Biochem. Physiol. 2020, 105, e21747. [CrossRef]

9. Shoukat, R.F.; Hassan, B.; Shakeel, M.; Zafar, J.; Li, S.; Freed, S.; Xu, X.; Jin, F. Pathogenicity and transgenerational effects of Metarhizium anisopliae on the demographic parameters of Aedes albopictus (Culicidae: Diptera). J. Med. Entomol. 2020, 57, 677-685. [CrossRef]

10. Zafar, J.; Freed, S.; Khan, B.A.; Farooq, M. Effectiveness of Beauveria bassiana against cotton whitefly, Bemisia tabaci (Gennadius) (Aleyrodidae: Homoptera) on different host plants. Pak. J. Zool. 2016, 48, 91-99.

11. Shoukat, R.F.; Freed, S.; Kanwar, W.A. Assessment of binary mixtures of entomopathogenic fungi and chemical insecticides on biological parameters of Culex pipiens (Diptera: Culicidae) under laboratory and field conditions. Pak. J. Zool. 2018, 50, 299-309. [CrossRef]

12. Mwamburi, L.A. Endophytic fungi, Beauveria bassiana and Metarhizium anisopliae, confer control of the fall armyworm, Spodoptera frugiperda (JE Smith) (Lepidoptera: Noctuidae), in two tomato varieties. Egypt. J. Biol Pest. Control. 2021, 31, 1-6. [CrossRef]

13. Evans, J.; Aronstein, K.; Chen, Y.P.; Hetru, C.; Imler, J.L.; Jiang, H.; Kanost, M.; Thompson, G.; Zou, Z.; Hultmark, D. Immune pathways and defence mechanisms in honey bees Apis mellifera. Insect Mol. Biol. 2006, 15, 645-656. [CrossRef]

14. Zafar, J.; Shoukat, R.F.; Zhang, Y.; Freed, S.; Xu, X.; Jin, F. Metarhizium anisopliae challenges immunity and demography of Plutella xylostella. Insects 2020, 11, 694. [CrossRef]

15. O'Brien, J.; Hayder, H.; Zayed, Y.; Peng, C. Overview of microRNA biogenesis, mechanisms of actions, and circulation. Front. Endocrinol. 2018, 9, 402. [CrossRef]

16. Lucas, K.J.; Zhao, B.; Liu, S.; Raikhel, A.S. Regulation of physiological processes by microRNAs in insects. Curr. Opin. Insect Sci. 2015, 11, 1-7. [CrossRef]

17. Ylla, G.; Piulachs, M.-D.; Belles, X. Comparative analysis of miRNA expression during the development of insects of different metamorphosis modes and germ-band types. BMC Genom. 2017, 18, 1-13. [CrossRef]

18. Li, X.; Guo, L.; Zhou, X.; Gao, X.; Liang, P. miRNAs regulated overexpression of ryanodine receptor is involved in chlorantraniliprole resistance in Plutella xylostella (L.). Sci. Rep. 2015, 5, 1-9. [CrossRef]

19. Jiang, S.; Wu, H.; Liu, H.; Zheng, J.; Lin, Y.; Chen, H. The overexpression of insect endogenous small RNAs in transgenic rice inhibits growth and delays pupation of striped stem borer (Chilo suppressalis). Pest. Manag. Sci. 2017, 73, 1453-1461. [CrossRef]

20. Etebari, K.; Asgari, S. Conserved microRNA miR-8 blocks activation of the toll pathway by upregulating serpin 27 transcripts. RNA Biol. 2013, 10, 1356-1364. [CrossRef]

21. Yang, M.; Wang, Y.; Jiang, F.; Song, T.; Wang, H.; Liu, Q.; Zhang, J.; Zhang, J.; Kang, L. miR-71 and miR-263 jointly regulate target genes chitin synthase and chitinase to control locust molting. PLoS Genet. 2016, 12, e1006257. [CrossRef]

22. Liu, Z.; Ling, L.; Xu, J.; Zeng, B.; Huang, Y.; Shang, P.; Tan, A. MicroRNA-14 regulates larval development time in Bombyx mori. Insect Biochem. Mol. Biol. 2018, 93, 57-65. [CrossRef]

23. Zhang, X.; Zheng, Y.; Cao, X.; Ren, R.; Yu, X.-Q.; Jiang, H. Identification and profiling of Manduca sexta microRNAs and their possible roles in regulating specific transcripts in fat body, hemocytes, and midgut. Insect Biochem. Mol. Biol. 2015, 62, 11-22. [CrossRef]

24. Vilcinskas, A. Evolutionary ecology of parasitic fungi and their host insects. Fungal Ecol. 2019, 38, 12-20. [CrossRef]

25. Roy, S.; Saha, T.T.; Zou, Z.; Raikhel, A.S. Regulatory pathways controlling female insect reproduction. Annu. Rev. Entomol. 2018, 63, 489-511. [CrossRef] 
26. Lin, J.; Yu, X.-Q.; Wang, Q.; Tao, X.; Li, J.; Zhang, S.; Xia, X.; You, M. Immune responses to Bacillus thuringiensis in the midgut of the diamondback moth, Plutella xylostella. Dev. Comp. Immunol. 2020, 107, 103661. [CrossRef]

27. Santos, C.G.; Humann, F.C.; Hartfelder, K. Juvenile hormone signaling in insect oogenesis. Curr. Opin. Insect Sci. 2019, 31, 43-48. [CrossRef]

28. Takeda, M. Structures and functions of insect midgut: The regulatory mechanisms by peptides, proteins and related compounds. In Hemolymph Proteins and Functional Peptides: Recent Advances in Insects and Other Arthropods; Tufail, M., Takeda, M., Eds.; Bentham Science Publishers: Sharjah, United Arab Emirates, 2012; Volume 1, pp. 94-110. [CrossRef]

29. Biswas, T.; Joop, G.; Rafaluk-Mohr, C. Cross-resistance: A consequence of bi-partite host-parasite coevolution. Insects 2018, 9, 28. [CrossRef]

30. Batta, Y.A. Efficacy of two species of entomopathogenic fungi against the stored-grain pest, Sitophilus granarius L. (Curculionidae: Coleoptera), via oral ingestion. Egypt. J. Biol. Pest. Control 2018, 28, 44. [CrossRef]

31. Wei, G.; Lai, Y.; Wang, G.; Chen, H.; Li, F.; Wang, S. Insect pathogenic fungus interacts with the gut microbiota to accelerate mosquito mortality. Proc. Natl. Acad. Sci. USA 2017, 114, 5994-5999. [CrossRef]

32. Ibrahim, S.A.M.; Taha, A.M.; Salem, H.H.A. Fungal infection causes serious effects on cuticle and midgut of the greater wax moth, Galleria mellonella. Egypt. Acad. J. Biol. Sci. 2019, 12, 1-8. [CrossRef]

33. Ibrahim, A.A.; Haroun, B.M.; El-Fekky, F.A.; Bekhiet, H.K. Effect of secondary metabolites from three entomopathogenic fungi on the cotton leaf worm, Spodoptera littoralis (Boisd.). Egypt. J. Agric. Res. 2012, 90, 575-587. [CrossRef]

34. Intodia, A.; Prasad, A.; Veerwal, B. Histopathology of Beauveria bassiana (balsamo) vuillemin, an entomopathogenic fungus, infection in the midgut of termite, Odontotermes obesus (r.) Worker. Int. J. Recent Sci. Res. 2019, 10, 34326-34330. [CrossRef]

35. Chavan, J.; Gaikwad, Y.; Chougale, A.; Bhawane, G. Curative effect of ethanolic plant extractives against Beauveria bassiana infection in silkworm, Bombyx mori 1.: Histopathological observations on midgut. Int. J. Anim. Biol. 2015, 1, $266-272$.

36. Zhou, Q.; Yang, Y.-C.; Shen, C.; He, C.-T.; Yuan, J.-G.; Yang, Z.-Y. Comparative analysis between low-and high-cadmiumaccumulating cultivars of Brassica parachinensis to identify difference of cadmium-induced microRNA and their targets. Plant. Soil 2017, 420, 223-237. [CrossRef]

37. Shakeel, M.; Rodriguez, A.; Tahir, U.B.; Jin, F. Gene expression studies of reference genes for quantitative real-time PCR: An overview in insects. Biotechnol. Lett. 2018, 40, 227-236. [CrossRef]

38. Livak, K.J.; Schmittgen, T.D. Analysis of relative gene expression data using real-time quantitative PCR and the $2^{-\Delta \Delta C T}$ method. Methods 2001, 25, 402-408. [CrossRef]

39. Etebari, K.; Afrad, M.; Tang, B.; Silva, R.; Furlong, M.; Asgari, S. Involvement of microRNA miR-2b-3p in regulation of metabolic resistance to insecticides in Plutella xylostella. Insect Mol. Biol. 2018, 27, 478-491. [CrossRef]

40. Asgari, S.; Zareie, R.; Zhang, G.; Schmidt, O. Isolation and characterization of a novel venom protein from an endoparasitoid, Cotesia rubecula (Hym: Braconidae). Arch. Insect Biochem. 2003, 53, 92-100. [CrossRef]

41. Calabrese, J.M.; Seila, A.C.; Yeo, G.W.; Sharp, P.A. RNA sequence analysis defines Dicer's role in mouse embryonic stem cells. Proc. Natl. Acad. Sci. USA 2007, 104, 18097-18102. [CrossRef]

42. Etebari, K.; Asgari, S. Revised annotation of Plutella xylostella microRNAs and their genome-wide target identification. Insect Mol. Biol. 2016, 25, 788-799. [CrossRef]

43. Shakeel, M.; Xu, X.; Xu, J.; Li, S.; Yu, J.; Zhou, X.; Xu, X.; Hu, Q.; Yu, X.; Jin, F. Genome-wide identification of Destruxin A-responsive immunity-related microRNAs in diamondback moth, Plutella xylostella. Front. Immunol. 2018, 9, 185. [CrossRef]

44. Xu, J.; Xu, X.; Li, S.; Wang, S.; Xu, X.; Zhou, X.; Yu, J.; Yu, X.; Shakeel, M.; Jin, F. Genome-wide profiling of Plutella xylostella immunity-related miRNAs after Isaria fumosorosea infection. Front. Physiol. 2017, 8, 1054. [CrossRef]

45. Li, S.; Xu, X.; Zheng, Z.; Zheng, J.; Shakeel, M.; Jin, F. MicroRNA expression profiling of Plutella xylostella after challenge with $B$. thuringiensis. Dev. Comp. Immunol. 2019, 93, 115-124. [CrossRef]

46. Hemmati, S.A.; Mehrabadi, M. Structural ensemble-based computational analysis of trypsin enzyme genes discovered highly conserved peptide motifs in insects. Arch. Phytopathol. 2020, 53, 335-354. [CrossRef]

47. Macedo, M.L.R.; Durigan, R.A.; da Silva, D.S.; Marangoni, S.; Freire, M.d.G.M.; Parra, J.R.P. Adenanthera pavonina trypsin inhibitor retard growth of Anagasta kuehniella (Lepidoptera: Pyralidae). Arch. Insect Biochem. Physiol. 2010, 73, 213-231. [CrossRef]

48. Farida, B.; Sonia, H.; Hakima, M.-K.; Fatma, B.; Fatma, H. Histological changes in the larvae of the domestic mosquito Culex pipiens treated with the entomopathogenic fungus Beauveria bassiana. Sci. Res. Essays 2018, 13, 1-10. [CrossRef]

49. Alves, S.; Pereira, R. Microbial control of insects. In Physiological Disorders Caused by Entomopathogens; Publisher of the Foundation for Agrarian Studies Luiz de Queiroz Piracicaba. FEALQ: Sao Dimas, Piracicaba, Brazil, 1998; pp. $39-53$.

50. Toledo, A.V.; Lenicov, A.M.M.d.R.; Lastra, C.C.L. Histopathology caused by the entomopathogenic fungi, Beauveria bassiana and Metarhizium anisopliae, in the adult planthopper, Peregrinus maidis, a maize virus vector. J. Insect Sci. 2010, 10, 35. [CrossRef]

51. Acuña, S.M.; Floeter-Winter, L.M.; Muxel, S.M. MicroRNAs: Biological regulators in pathogen-host interactions. Cells 2020, 9, 113. [CrossRef]

52. Boulan, L.; Martín, D.; Milán, M. Bantam miRNA promotes systemic growth by connecting insulin signaling and ecdysone production. Curr. Biol. 2013, 23, 473-478. [CrossRef]

53. Fullaondo, A.; Lee, S.Y. Identification of putative miRNA involved in Drosophila melanogaster immune response. Dev. Comp. Immunol. 2012, 36, 267-273. [CrossRef] 
54. Etebari, K.; Hussain, M.; Asgari, S. Identification of microRNAs from Plutella xylostella larvae associated with parasitization by Diadegma semiclausum. Insect Biochem. Mol. Biol. 2013, 43, 309-318. [CrossRef]

55. Zhu, B.; Li, X.; Liu, Y.; Gao, X.; Liang, P. Global identification of microRNAs associated with chlorantraniliprole resistance in diamondback moth Plutella xylostella (L.). Sci. Rep. 2017, 7, 1-12. [CrossRef]

56. Asgari, S. MicroRNA functions in insects. Insect Biochem. Mol. Biol. 2013, 43, 388-397. [CrossRef]

57. Zhou, Y.; Liu, Y.; Yan, H.; Li, Y.; Zhang, H.; Xu, J.; Puthiyakunnon, S.; Chen, X. miR-281, an abundant midgut-specific miRNA of the vector mosquito Aedes albopictus enhances dengue virus replication. Parasit. Vectors. 2014, 7, 488. [CrossRef]

58. Luo, W.; Huang, L.-X.; Qin, S.-K.; Zhang, X.; Feng, Q.-L.; Gu, J.; Huang, L.-H. Multiple microRNAs control ecdysone signaling in the midgut of Spodoptera litura. Insect Sci. 2020, 27, 1208-1223. [CrossRef]

59. Caygill, E.E.; Johnston, L.A. Temporal regulation of metamorphic processes in Drosophila by the let-7 and miR-125 heterochronic microRNAs. Curr. Biol. 2008, 18, 943-950. [CrossRef]

60. Garbuzov, A.; Tatar, M. Hormonal regulation of Drosophila microRNA let-7 and miR-125 that target innate immunity. Fly 2010, 4 , 306-311. [CrossRef]

61. Sunkar, R.; Jagadeeswaran, G. In silico identification of conserved microRNAs in large number of diverse plant species. BMC Plant Biol. 2008, 8, 37. [CrossRef]

62. Vilcinskas, A. The role of epigenetics in host-parasite coevolution: Lessons from the model host insects Galleria mellonella and Tribolium castaneum. Zoology 2016, 119, 273-280. [CrossRef]

63. Skalsky, R.L.; Vanlandingham, D.L.; Scholle, F.; Higgs, S.; Cullen, B.R. Identification of microRNAs expressed in two mosquito vectors, Aedes albopictus and Culex quinquefasciatus. BMC Genom. 2010, 11, 119. [CrossRef] [PubMed]

64. Li, R.; Huang, Y.; Zhang, Q.; Zhou, H.; Jin, P.; Ma, F. The miR-317 functions as a negative regulator of toll immune response and influences Drosophila survival. Dev. Comp. Immunol. 2019, 95, 19-27. [CrossRef]

65. Yang, J.; Xu, X.; Lin, S.; Chen, S.; Lin, G.; Song, Q.; Bai, J.; You, M.; Xie, M. Profiling of microRNAs in midguts of Plutella xylostella provides novel insights into the Bacillus thuringiensis resistance. Front. Genet. 2021, 12, 1690. [CrossRef] [PubMed]

66. Marco, A.; Hooks, K.; Griffiths-Jones, S. Evolution and function of the extended miR-2 microRNA family. RNA Biol. 2012, 9 , 242-248. [CrossRef] [PubMed]

67. Lozano, J.; Montañez, R.; Belles, X. MiR-2 family regulates insect metamorphosis by controlling the juvenile hormone signaling pathway. Proc. Natl. Acad. Sci. USA 2015, 112, 3740-3745. [CrossRef]

68. He, K.; Sun, Y.; Xiao, H.; Ge, C.; Li, F.; Han, Z. Multiple miRNAs jointly regulate the biosynthesis of ecdysteroid in the holometabolous insects, Chilo suppressalis. RNA 2017, 23, 1817-1833. [CrossRef]

69. Jiang, J.; Ge, X.; Li, Z.; Wang, Y.; Song, Q.; Stanley, D.W.; Tan, A.; Huang, Y. MicroRNA-281 regulates the expression of ecdysone receptor $(\mathrm{EcR})$ isoform B in the silkworm, Bombyx mori. Insect Biochem. Mol. Biol. 2013, 43, 692-700. [CrossRef]

70. Zhu, Y.C.; Liu, X.; Maddur, A.A.; Oppert, B.; Chen, M.-S. Cloning and characterization of chymotrypsin-and trypsin-like cDNAs from the gut of the Hessian fly [Mayetiola destructor (Say)]. Insect Biochem. Mol. Biol. 2005, 35, 23-32. [CrossRef]

71. Jayachandran, B.; Hussain, M.; Asgari, S. Regulation of Helicoverpa armigera ecdysone receptor by miR-14 and its potential link to baculovirus infection. J. Invertebr. Pathol. 2013, 114, 151-157. [CrossRef]

72. Zotti, M.; Dos Santos, E.A.; Cagliari, D.; Christiaens, O.; Taning, C.N.T.; Smagghe, G. RNA interference technology in crop protection against arthropod pests, pathogens and nematodes. Pest. Manag. Sci. 2018, 74, 1239-1250. [CrossRef]

73. Zhang, Y.L.; Huang, Q.X.; Yin, G.H.; Lee, S.; Jia, R.Z.; Liu, Z.X.; Yu, N.T.; Pennerman, K.K.; Chen, X.; Guo, A.P. Identification of microRNAs by small RNA deep sequencing for synthetic microRNA mimics to control Spodoptera exigua. Gene 2015, 557, $215-221$. [CrossRef]

74. Agrawal, A.; Rajamani, V.; Reddy, V.S.; Mukherjee, S.K.; Bhatnagar, R.K. Transgenic plants over-expressing insect-specific microRNA acquire insecticidal activity against Helicoverpa armigera: An alternative to Bt-toxin technology. Transgenic Res. 2015, 24, 791-801. [CrossRef]

75. Xu, D.; Xue, Q.; McElroy, D.; Mawal, Y.; Hilder, V.A.; Wu, R. Constitutive expression of a cowpea trypsin inhibitor gene, CpTi, in transgenic rice plants confers resistance to two major rice insect pests. Mol. Breed. 1996, 2, 167-173. [CrossRef]

76. Singh, D.; Kesavan, A.K.; Sohal, S.K. Exploration of anti-insect potential of trypsin inhibitor purified from seeds of Sapindus mukorossi against Bactrocera cucurbitae. Sci. Rep. 2019, 9, 1-14. [CrossRef]

77. Mukherjee, K.; Vilcinskas, A. The entomopathogenic fungus Metarhizium robertsii communicates with the insect host Galleria mellonella during infection. Virulence 2018, 9, 402-413. [CrossRef]

78. Li, X.; Ren, X.; Liu, Y.; Smagghe, G.; Liang, P.; Gao, X. MiR-189942 regulates fufenozide susceptibility by modulating ecdysone receptor isoform B in Plutella xylostella (L.). Pestic. Biochem. Physiol. 2020, 163, 235-240. [CrossRef]

79. Zhenghao, W.; Miao, J.; Yanfeng, Z.; Guilin, D.; Guangchun, C.; Xiangqun, N.; Changzhong, L.; Guangjun, W.; Zehua, Z. Effects of different inhibitors on digestive enzyme and detoxification enzyme in midgut of Locusta migratoria manilensis during Metarhizium anisopliae infection. Chin. J. Biol. 2016, 32, 756-761. [CrossRef] 